\title{
The importance of History of Cartography in the Geography teaching
}

\author{
Carla Cristina R. G. de Sena ${ }^{\text {a, }}$ * \\ a UNESP, cacrisusp@gmail.com \\ * Corresponding author
}

Keywords: history of cartography, geography teaching, cartography teaching

\begin{abstract}
:
Cartography and Geography have always been interconnected. In basic education, they are often mistaken as one, since maps materialize the most diverse topics approached by the geographic science. However, for many years the maps used in schools were considered simple illustrations, working as accessories to help in location and memorization.
\end{abstract}

Even though the studies about learning through the map and not only of the map (OLIVEIRA, 2007) are from the 1970 decade, it was only in the 1990's, with the publication of the Brazilian Curriculum Parameters (Parâmetros Curriculares Nacionais - PCN), that the concern about the formation of critical reader students and, primarily, producers of maps has left the academia and provoked the insertion of specific cartography themes in textbooks and official curriculums in Brazil.

Scale, orientation, geographic coordinates, etc. have become part of the Geography classes on a daily basis, or at least they should have. The same has happened to the history of Cartography, which started to be inserted in textbooks, although in the form of illustration and curiosity.

This thematic, when worked in the basic education, helps in the students' reflection about the different world perspectives that the humankind built along millenniums. The presentation of maps from ancient age, such as the Babylonians and Greeks, allows the establishment of parameters for the discussion of their influence in social groups. The representation of the Middle Age and the great leap of Cartography with the navigations of the XV and XVI demonstrate the capacity of maps to serve the interests of dominant groups from that time and their strategic power.

Thinking about the importance of this kind of map, History and Geography textbooks used in the last years of elementary school and in high school were analyzed to identify the presence of old maps and how they are approached. The research concluded that most old maps are used as illustrations, as there are not meaningful activities related to the analysis of these maps and that, when those activities existed, they were restricted to the chapters that dealt specifically about the history of cartography and the origin of maps.

In this way, the teacher needs elements to go beyond of what is proposed by the textbook, and in order to do that, they need to be in touch with the history of Cartography not just as simple curiosity, but as a possible content to be used in the spatial dynamic comprehension. Helping students to elaborate critical analyses about what used to be represented on the maps and how it used to be done. Hence, it is possible that those students understand that, as a human product, maps are full of intentions and ideologies.

This paper presents a reflection about the importance of the discussion of the history of Cartography in Geography undergraduate courses from the experience of approaching this theme in the School Cartography class, raising questions about the power of the maps in the context in which they were produced and the "load of information they broadcast in human terms" (HARLEY, 2009 p. 10), valuing the potential of working with maps in different periods during the teacher's education. 